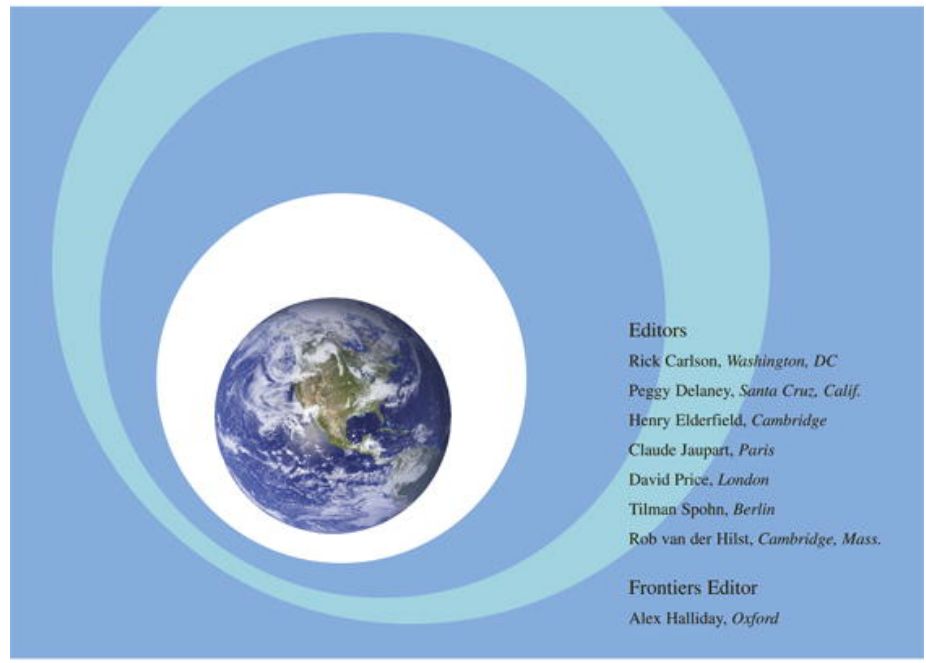

This article was published in an Elsevier journal. The attached copy

is furnished to the author for non-commercial research and education use, including for instruction at the author's institution, sharing with colleagues and providing to institution administration.

Other uses, including reproduction and distribution, or selling or licensing copies, or posting to personal, institutional or third party websites are prohibited.

In most cases authors are permitted to post their version of the article (e.g. in Word or Tex form) to their personal website or institutional repository. Authors requiring further information regarding Elsevier's archiving and manuscript policies are encouraged to visit: 


\title{
Characterization of topographic steady state in Taiwan
}

\author{
Drew B. Stolar ${ }^{\mathrm{a}, \mathrm{b}, *}$, Sean D. Willett ${ }^{\mathrm{a}, \mathrm{c}}$, David R. Montgomery ${ }^{\mathrm{a}}$ \\ a Department of Earth and Space Sciences, Box 351310, University of Washington, Seattle, WA 98195, USA \\ ${ }^{\mathrm{b}}$ School of Earth and Space Exploration, Box 871404, Arizona State University, Tempe, AZ 85287, USA \\ ${ }^{\mathrm{c}}$ Geological Institute, Swiss Federal Institute of Technology Zurich, 8092 Zürich, Switzerland
}

Received 24 May 2006; received in revised form 1 June 2007; accepted 8 July 2007

Available online 2 August 2007

Editor: C.P. Jaupart

\begin{abstract}
The arc-continent collision in Taiwan has resulted in surface uplift, high relief and high rates of erosion. Because the collision is older in the north and has propagated southward, Taiwan offers the opportunity to study the evolution of topography as it evolves towards a large-scale steady state. In this paper, we analyze a 40-m digital elevation model of Taiwan to determine how topographic steady state is expressed in the landscape; particular attention is paid to the eastern Central Range, where major drainage basins are approximately aligned in the direction of the collision propagation. Analyses of orogen size, regional topographic slope, drainage basin hypsometry, and local topographic slope reveal a geomorphological transition 100-125 km north of the southern tip of the island. To the south of this transition, topographic characteristics change with distance along the island; to the north, these characteristics are relatively constant, which we interpret as representing large-scale topographic steady state. Assuming that the collision has propagated southward at a rate of $55 \mathrm{~mm} / \mathrm{yr}$, the time to topographic steady state is $1.8-2.3$ Myr after emergence above sea level. Within the steady state region, we evaluate regional variability in the topography and find that the most prominent deviations from a steady form are associated with large-scale structures, though our analyses of local topographic slope and river profile form suggest that spatial variations in rock strength and rock uplift rate also contribute to regional topographic variability. (C) 2007 Elsevier B.V. All rights reserved.
\end{abstract}

Keywords: topography; erosion; tectonics; GIS

\section{Introduction}

The strong negative feedback between local topographic relief and the rate of surface lowering by erosion (Ahnert, 1970; Montgomery and Brandon, 2002) has important implications for mountain range evolution

\footnotetext{
* Corresponding author. School of Earth and Space Exploration, Box 871404, Arizona State University, Tempe, AZ 85287, USA. Tel.: +1 206384 9384; fax: +1 4809658102 .

E-mail addresses: dstolar@asu.edu (D.B. Stolar), swillett@erdw.ethz.ch (S.D. Willett), dave@ess.washington.edu (D.R. Montgomery).
}

(Willett and Brandon, 2002). In convergent plate tectonic settings, surface erosion encourages evolution of the landscape towards a state in which rates of constructive and destructive processes balance. Many theoretical models of landscape evolution suggest that topography can achieve a steady state (SS), such that the rates of rock uplift and erosion are equal everywhere in the landscape (Koons, 1990; Willgoose et al., 1991a; Howard, 1994; Whipple and Tucker, 1999). In natural settings, however, topographic SS is likely to exist at only the broadest spatial scales, where measures such as the orogen size and mean relief are relatively constant through time (Suppe, 1981); the finer-scale variability of 
topographic characteristics at SS are not as well defined. Finer-scale topography could behave like topography over larger scales and exhibit some mean form about which there is some variation. Alternatively, it is possible that the inherent variability of topography obscures the expression of topographic SS at small scales. Here, we examine the characteristics of the topography in Taiwan, which is presumably at SS, thereby exploring how topographic SS is expressed at a variety of scales in a landscape.

Taiwan is an excellent natural laboratory in which to address this question. Suppe (1981) recognized that the collision between the Eurasian continental margin and the Luzon Arc has propagated southwards over the past 5-7 Myr. As a result, the age of collision and duration of subsequent sub-aerial erosion increase progressively to the north. Using the implied equivalence between distance from the southern tip of the island and duration of sub-aerial landscape evolution, he interpreted the northward increase of mountain width and cross- sectional area towards constant values as representing the evolution toward a large-scale topographic SS. His analysis also showed that the pre-SS and SS landscapes span nearly $125 \mathrm{~km}$ and $150 \mathrm{~km}$ along the axis of Taiwan, respectively. Thus, the topography of Taiwan represents an opportunity, not only to compare characteristics of pre-SS and SS landscapes, but also to determine the spatial, and perhaps temporal, variability of topography within a SS landscape.

In this paper, we use a high-resolution (40-m grid) digital elevation model (DEM) of Taiwan and gridbased analysis tools to characterize the topography of Taiwan. Our analysis takes advantage of the space-fortime equivalence by measuring topography within cross-island swaths and drainage basins. Projecting the measurements onto an along-island transect allows for trends in topography to be interpreted as the record of progressive landscape evolution, and allows for quantification of topographic variability within the steadystate region.

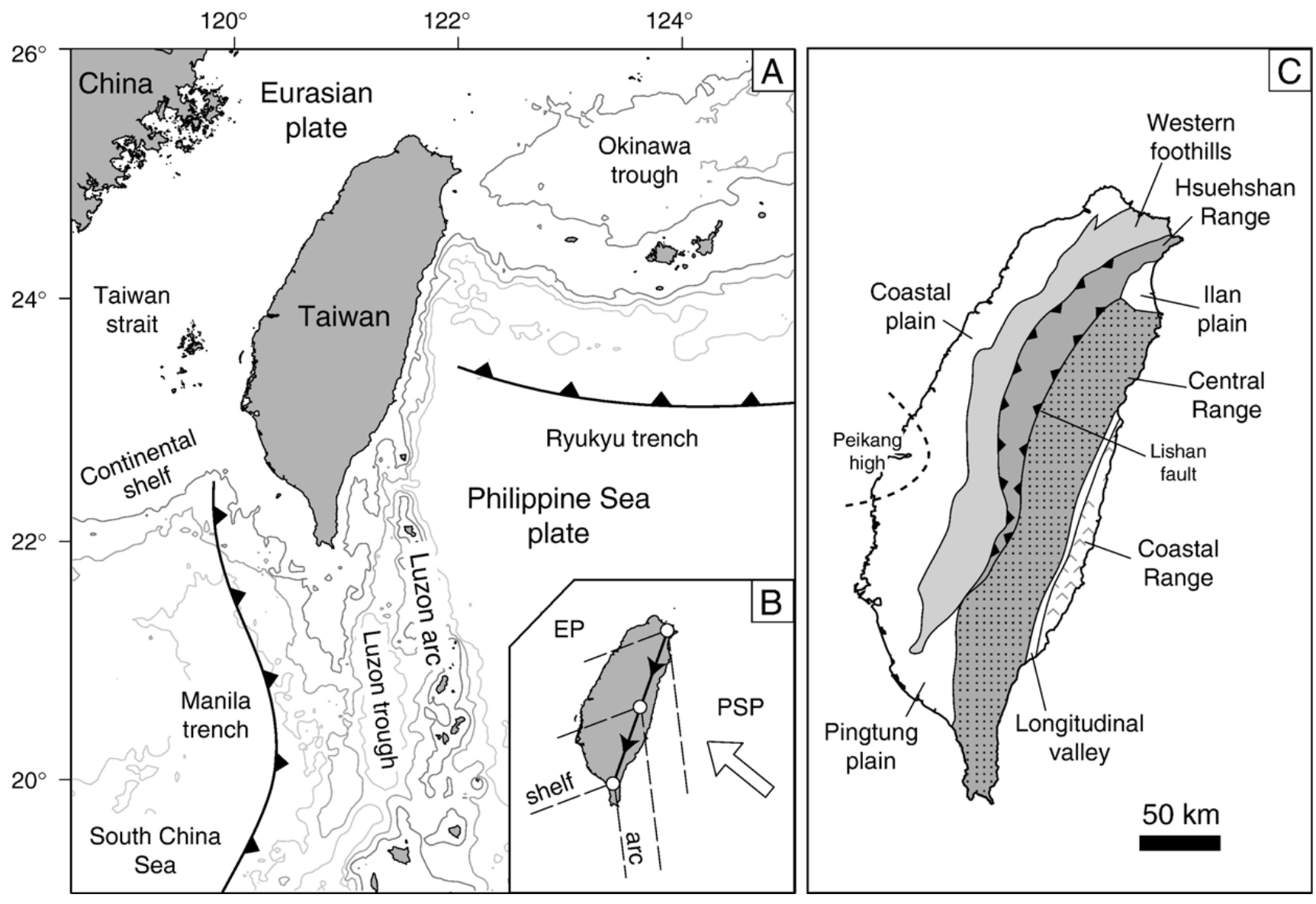

Fig. 1. A) Regional tectonic setting of Taiwan, with 1-, 2-, and 3-km bathymetric contours. B) Oblique collision of the continental shelf of the Eurasian plate (EP) and the Luzon arc leads to propagation of the collision towards the south. Open circles show the location of the onset of collision at three different times. C) Physiographic domains of Taiwan. Also shown are the Lishan fault and the Peikang basement high. 


\section{Overview of the tectonic and geologic setting}

Taiwan lies along the subduction zone boundary between the Eurasian plate (EP) and the Philippine Sea plate (PSP) (Fig. 1A). Convergence between the two plates occurs at $82 \mathrm{~mm} / \mathrm{yr}$ (Yu et al., 1997) and is accommodated by two subduction zones of opposite polarity (Fig. 1A). In the south, the oceanic portion of the EP subducts beneath the PSP at the Manila trench. In the north, the PSP subducts beneath the EP at the Ryuku trench. The northeastern corner of Taiwan (see Ilan plain in Fig. 1C) is the western limit of the backarc basin of this subduction zone. Here, backarc extension destroys the Taiwan orogen topography (Teng, 1996).

The Taiwan arc-continent collision zone lies between the two subduction zones and is the consequence of the oblique collision of the Luzon Arc with the continental shelf of the EP (Fig. 1B). The margin-arc obliquity has resulted in the southward propagation of the collision since its initiation at 5-7 Ma (Byrne and Liu, 2002). Thus, there is a space-time equivalence that relates the age of the collision to the distance along the axis of the

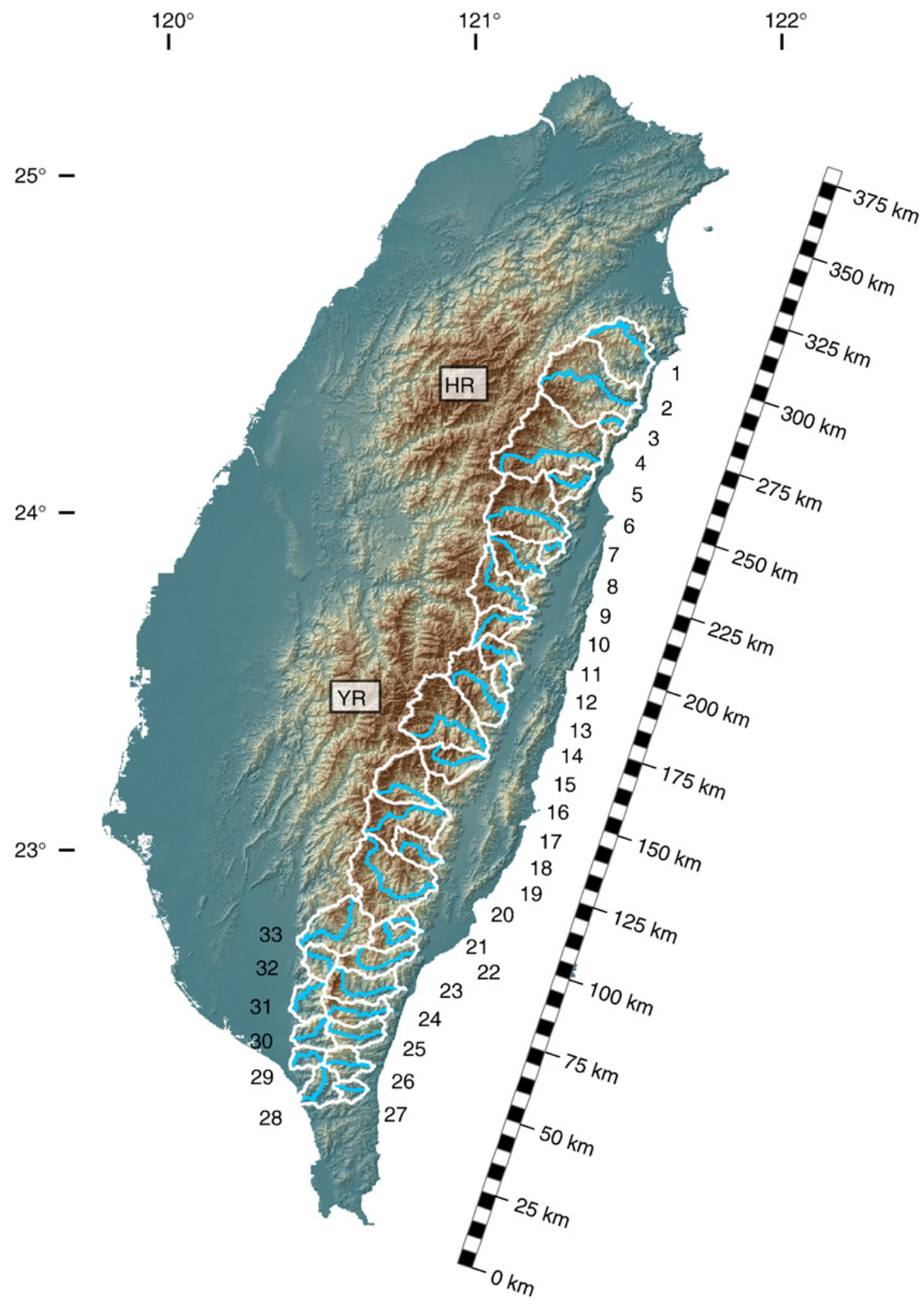

Fig. 2. DEM (40-m resolution) of Taiwan with Central Range (CR) basins and river profiles used in this study highlighted. HR: Hsuehshan Range, YR: Yushan Range. 
island. Suppe (1981) estimated the propagation rate at $90 \mathrm{~mm} / \mathrm{yr}$ based on the assumption that the obliquity of the collision is best described by the angle between the Eurasian continental shelf and the axis of the island. However, paleomagnetic data (Lee et al., 1991) demonstrate that the island has undergone clockwise rotation during collision. Byrne and Liu (2002) argued that the collision is better described by the angle between the continental margin and the unrotated Luzon Arc, such that the propagation rate is lower $(55 \mathrm{~mm} / \mathrm{yr})$.

Geology, tectonics and physiography are closely related in Taiwan. Almost all of the major tectonic domains of the island are the onshore continuations of extensive submarine features of the Eurasian-Philippine Sea plate boundary. The Coastal Range, which is the northern extension of the Luzon Arc, is composed primarily of arc-related volcanics and olistostromal deposits (Teng, 1987). The Longitudinal Valley (LV) merges offshore with the Luzon trough (Suppe, 1981) and has accommodated significant volumes of Miocene-topresent sediment, mainly from drainage basins in the eastern Central Range. Geodetic and creep-meter data indicate that the Coastal Range is being thrust over the $\mathrm{LV}$ at a rate of $17-30 \mathrm{~mm} / \mathrm{yr}$ (Yu et al., 1997; Lee et al., 2001). The Central Range (CR) consists of metamorphosed continental shelf sediments and a pre-Tertiary basement, which is exposed exclusively within the eastern CR and consists of greenschists, marbles and gneisses. The geodetic study of Yu et al. (1997) indicates that $50-60 \mathrm{~mm} / \mathrm{yr}$ of shortening is accommodated by deformation within and to the west of the CR. The Lishan Fault and the Hsuehshan Range (HR), a crustal-scale pop-up structure composed of slates and meta-sandstones (Clark et al., 1993), bound the CR to the west. Farther west are the Western Foothills, where faulting and fold growth have deformed Late Mioceneto-present foreland basin sediments (Suppe, 1981).

This brief overview of the setting of Taiwan indicates that not all regions of the island are relevant to our study. Because our goal is to characterize the landscape where surface erosion counteracts collision-driven accretion, we do not analyze the Coastal Range, the Longitudinal Valley, or the Coastal, Ilan and Pingtung plains. In the next Section, we measure the cross-sectional size and topographic slope within cross-island swaths.

\section{Cross-island swath analysis}

\subsection{Orogen size}

Characteristics such as the cross-sectional area and mean elevation should reflect the mass balance of an orogen. For instance, the cross-sectional area of a noneroding orogenic wedge that is fed by a steady accretionary flux increases linearly in time; given self-similar growth, the mean elevation should increase as the square root of time. Erosion of the wedge dampens growth and eventually leads to a topographic steady state.

We construct a set of 5-km wide swaths that are oriented perpendicular to the island axis and calculate the cross-sectional area, mean elevation, and maximum elevation of each swath. These values are then projected onto the orogen-parallel transect shown in Fig. 2. The values and smoothed values are shown in Fig. 3A.

Along the axial transect, the cross-sectional area and mean and maximum elevation increase from the southern tip of the island to the southern end of the LV $(\sim 125 \mathrm{~km}$ to the north). North of this point, these quantities attain roughly constant values until, at $275 \mathrm{~km}$ $\mathrm{N}$, they decrease rapidly towards the northern tip of the island.

From $125 \mathrm{~km} \mathrm{~N}$, the largest deviations from a constant orogen size are associated with physiographic features that, in some cases, are related to large-scale structures. The local maxima at $175 \mathrm{~km} \mathrm{~N}$ are associated with the Yushan Range (YR in Fig. 2), which is a consequence of the collision of the Peikang basement high with the Western Foothills (Liu et al., 2001). The local minima at $225 \mathrm{~km} \mathrm{~N}$ correspond to an embayment in the western Central Range centered about the Juoshuei river. Farther north, the local maxima at $275 \mathrm{~km} \mathrm{~N}$ are associated with the Hsuehshan Range (HR in Fig. 2). The decrease in size north of $275 \mathrm{~km}$ records the extensional destruction of Taiwan (Teng, 1996).

If we neglect the influence of the discrete structures noted above, the first-order trends in orogen size can be described by three segments: an increase from the southern tip of the island to $125 \mathrm{~km} \mathrm{~N}$, a constant value from $125 \mathrm{~km} \mathrm{~N}$ to $300 \mathrm{~km} \mathrm{~N}$, and a decrease from $300 \mathrm{~km} \mathrm{~N}$ to the northern end of the island. Taking the average values of the cross-sectional area, mean elevation, and maximum elevation between 125 and $300 \mathrm{~km} \mathrm{~N}$ to be $120 \mathrm{~km}^{2}, 1.25 \mathrm{~km}$, and $3.25 \mathrm{~km}$, respectively, the maximum deviation from the mean in each measure is approximately $30 \%, 20 \%$, and $12 \%$ over this same regional extent.

\subsection{Regional topographic slope}

In an orogenic wedge, the regional topographic slope in the across-strike direction has particular tectonic significance. Assuming that the wedge deforms frictionally and that the large-scale frictional properties of the wedge do not change with time, the taper angle, which is 


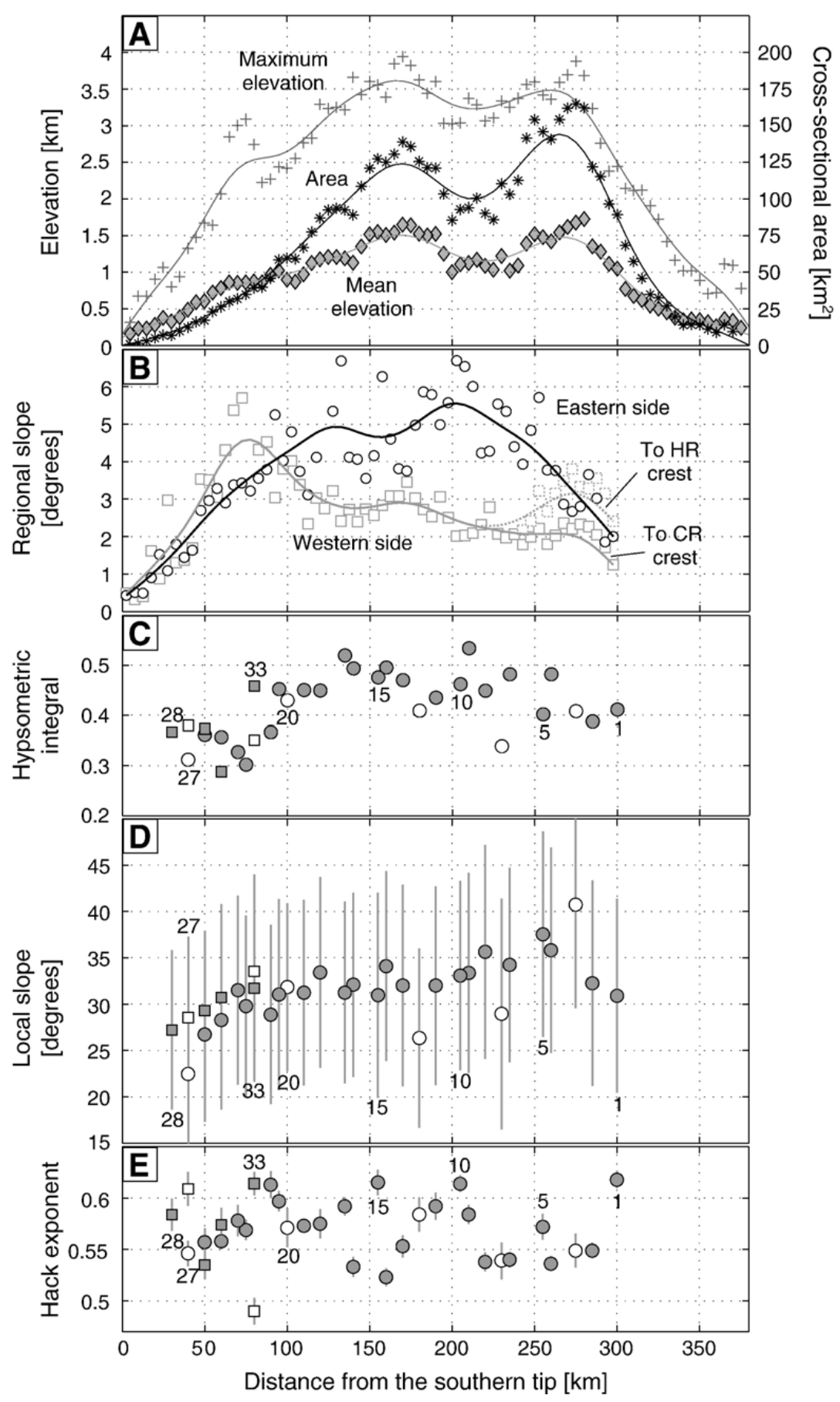

Fig. 3. A) Cross-sectional area $(*)$, and mean $(\diamond)$ and maximum $(+)$ elevation as a function of distance from the southern tip of the island. Smoothed functions for each data set are also shown. B) Regional slope of the western and eastern CR. Where the Hsuehshan Range (HR) is large, eastern slope is determined up to the HR crest (dashed squares) and up to the CR crest (squares). Average slopes are shown by lines with similar symbology. C) Hypsometric integral of ECR basins as a function of the distance of the basin outlet from the southern tip of the island. Small basins $\left(A<100 \mathrm{~km}^{2}\right)$ marked with open symbols, larger basins with filled symbols. Basins in the eastern CR are denoted by circles, basins in the western CR by squares. Note that selected basins are labeled by identification numbers that appear directly above or below the plotted circle. D) Mean and one standard deviation of local slope distributions within the CR basins. Symbology is the same as in Fig. 3C. E) Hack exponent of the main-stem rivers of the CR basins plotted with one standard error. Symbology is the same as in Fig. 3C.

the sum of the regional topographic slope and the dip of the basal decollement, should be steady through time (Dahlen, 1984). If the basal decollement maintains a steady dip, so does the regional topographic slope, and one would expect no change in regional slope with distance away from the southern tip of Taiwan. 
Alternatively, Hilley et al. (2004) propose that the regional topographic slope of an eroding wedge increases as the wedge increases in size until the accretionary and erosional fluxes balance. Given this expectation, the regional topographic slope is a possible indicator of topographic SS.

We estimate the regional slope of the sub-aerial portion of the orogen using mean elevation profiles from the cross-island swaths presented in the previous section. Where the range is characterized by only one major divide, slopes are determined by linear regression of the western and eastern segments (squares and circles in Fig. 3B, respectively). From $250 \mathrm{~km} \mathrm{~N}$ to $300 \mathrm{~km} \mathrm{~N}$, the Hsuehshan Range is as large or larger than the Central Range, and the western slope is determined by linear regression of segments that extend to both the HR crest (dashed squares in Fig. 3B) and the CR crest (squares in Fig. 3B). Smoothed trends are also shown in Fig. 3B.

The average eastern slope increases from near zero at the southern tip of the island to $4^{\circ}$ at $100 \mathrm{~km} \mathrm{~N}$, remains greater than $4^{\circ}$ until $250 \mathrm{~km} \mathrm{~N}$ and decreases to $2^{\circ}$ at $300 \mathrm{~km} \mathrm{~N}$. Note that the region of highest eastern slopes coincides with a prominent topographic embayment in the western side of the range that deflects the range divide to the east. The average western slope is also low near the southern tip of the island and increases to a maximum of $4.5^{\circ}$ at $75 \mathrm{~km} \mathrm{~N}$, which corresponds to a peak in maximum elevation (see Fig. 3A). North of $100 \mathrm{~km} \mathrm{~N}$, the western slope decreases slightly, with the exception of a small increase at $275 \mathrm{~km} \mathrm{~N}$, which corresponds to the development of the Hsuehshan Range.

At the swath-to-swath scale, the variance in regional topographic slopes seems to increase with the average slope value. Between $100 \mathrm{~km} \mathrm{~N}$ and $250 \mathrm{~km} \mathrm{~N}$, slopes on the steeper, eastern side often differ by more than $1^{\circ}-1.5^{\circ}$ from slopes from adjacent swaths. Within this same span, slopes on the western side rarely differ more than $0.5^{\circ}$ from values from adjacent swaths. Where western slopes are high (50 to $100 \mathrm{~km} \mathrm{~N}$ ), the variance is similar to that observed in the steeper portions of the eastern side.

\section{Drainage basin analysis}

In this section, we use a series of drainage basin analyses to further characterize the topography of Taiwan. This analysis is complicated in the western side of the range by longitudinal drainages with structurally-controlled boundaries. Given the lack of a representative distance or duration of erosion, we ignore all drainage basins on the western side of the island north of $100 \mathrm{~km} \mathrm{~N}$. We consider thirty three drainage basins from the eastern and western Central Range (Fig. 2). The basins range in area from 41 to $612 \mathrm{~km}^{2}$. The statistics calculated for small basins $\left(A<100 \mathrm{~km}^{2}\right)$ are often markedly different than those of adjacent, larger basins. Hence, we denote measurements from the smaller basins in Fig. 3 with open symbols.

\subsection{Basin hypsometry}

The probability distribution of elevation within a region, or the hypsometry, is thought to reflect the maturity of the landscape, along with the dominant tectonic and erosional processes. We quantify the hypsometry of the CR basins using a summary value, the hypsometric integral (Strahler, 1952). For a basin with minimum elevation, $z_{\min }$, and maximum elevation, $z_{\max }$, the hypsometric integral is the fraction of the basin higher than $z_{\text {mid }}=\left(z_{\min }+z_{\max }\right) / 2$. For example, in a basin encompassing a slightly incised plateau, much of the basin is higher than $z_{\text {mid }}$, and the hypsometric integral is greater than 0.5 .

We calculate the hypsometric integral for each of the $\mathrm{CR}$ drainage basins and plot the value against the distance of the basin outlet from the southern tip of the island (Fig. 3C). At the largest scale, the hypsometric integral values can be divided into two populations: the transition between the two occurs $\sim 100 \mathrm{~km}$ north of the southern tip of the island. Basins in the southern population (Basins 22-27 and 28-32) have lower hypsometric integral values, whereas the larger basins in the northern population (Basins 1-21 and 33) have values greater than 0.39 (i.e., basins in the north have more relative area at higher relative elevations).

North of $100 \mathrm{~km} \mathrm{~N}$, the hypsometric integral of adjacent large basins can differ by almost 0.1. The hypsometric integral of Basin 7, which does not reach the Central Range divide, differs by more than 0.1 from values for both adjacent basins.

\subsection{Local topographic slope}

Measures of local topographic slope in the Central Range should record the transition to threshold slopes, which are thought to characterize topographic SS in rapidly uplifting and eroding orogens like Taiwan (Burbank et al., 1996; Montgomery, 2001). We calculate probability distributions of local topographic slope within the hillslope portion of the CR drainage basins. The distributions are all roughly Gaussian in form, and there is no significant difference between trends in the mean, median or mode.

The mean and one standard deviation of the local slope distributions are shown in Fig. 3D. Mean slope 
increases from $23^{\circ}$ in Basin 27 and $27^{\circ}$ in Basin 28 to $31^{\circ}$ in Basin 20, remains constant $\left(30^{\circ}-35^{\circ}\right)$ from Basin 20 to Basin 10, and increases from $33^{\circ}$ in Basin 9 to a maximum of $41^{\circ}$ in Basin 3. Slopes in the WCR basins tend to be slightly greater than those in the southern ECR. The mean local slopes of large adjacent basins are almost always within $5^{\circ}$ of each other. The largest basinto-basin differences in mean local slope are associated

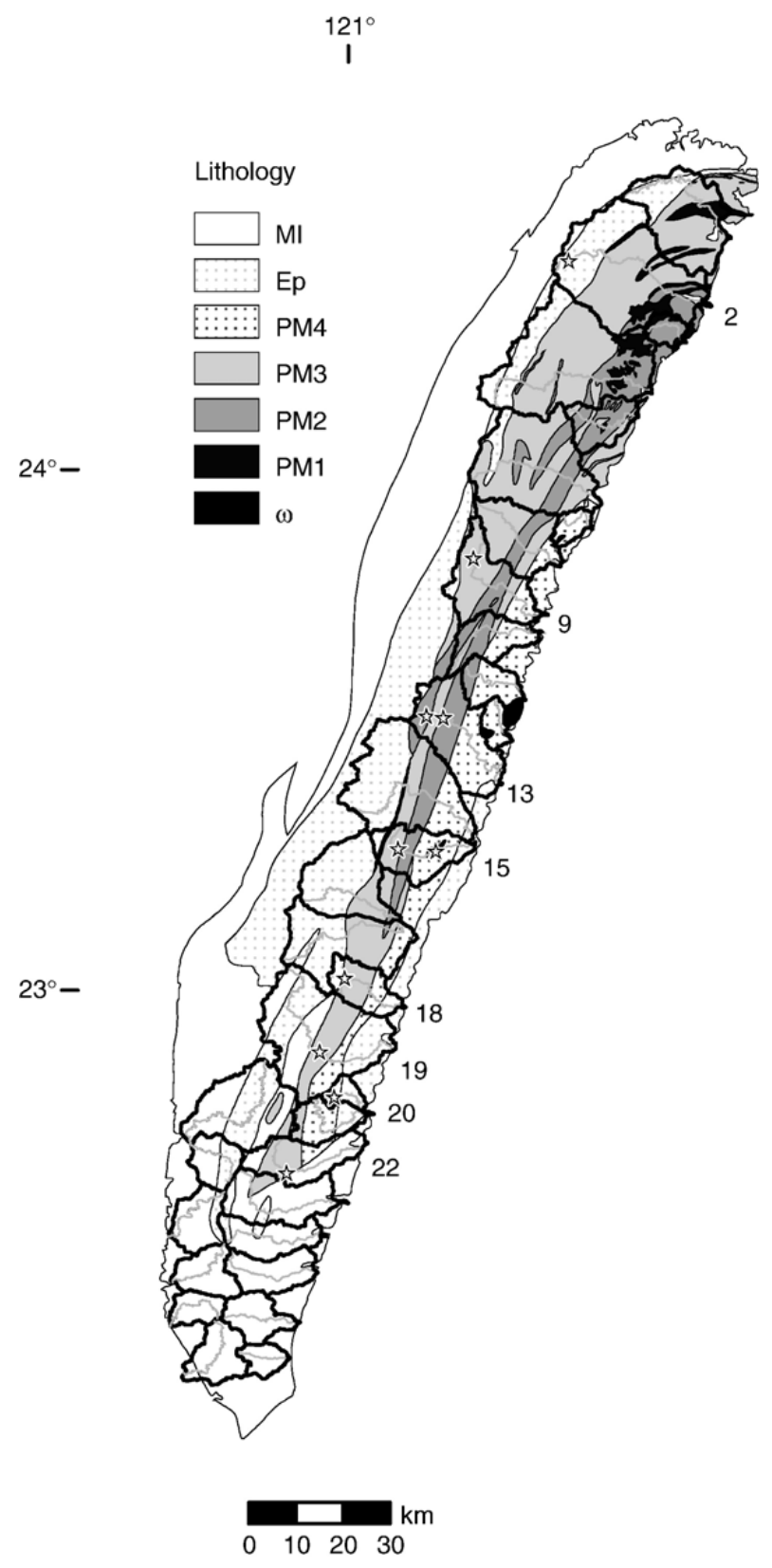

Fig. 4. Geology of the CR from Ho (1988). Legend: MI: Miocene argillites, slate, phyllite; Ep: Eocene slate, phyllite; PM4: PaleozoicMesozoic blackschist; PM3: Blackschist, greenschist, siliceous schist; PM2: Metamorphosed limestone; PM1: Gneisses and migmatite; $\omega$ : Mafic igneous rocks. CR basins are outlined in solid white lines, main-stem river profiles in thin gray lines. Prominent knickzones are denoted with stars.

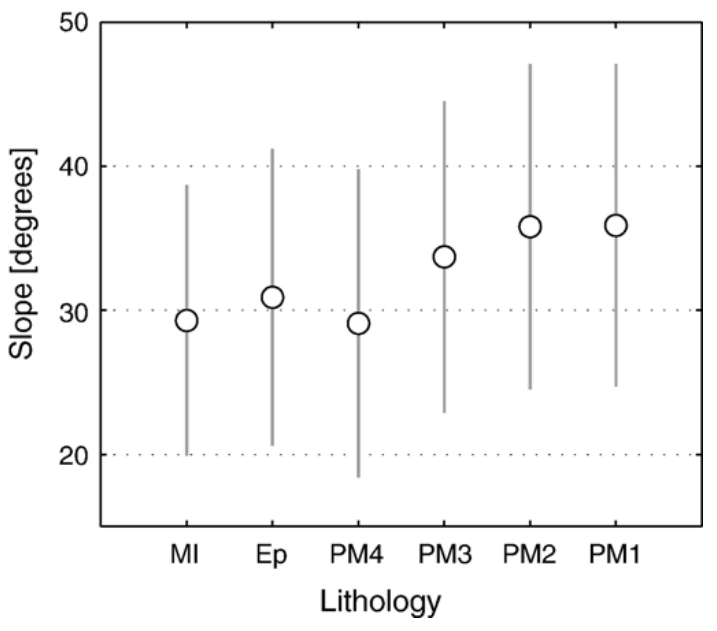

Fig. 5. Mean and one standard deviation of the local slope within Basins $10-20$ as a function of lithology. Geologic classifications are the same as in Fig. 4.

with three smaller basins (Basins 3, 7 and 12), none of which reach the main Central Range divide.

Using the 1:500,000 geologic map of Ho (1988), we note a correlation between mean local slope and average lithology (Figs. 4 and 5). Where the mean local slope of large drainage basins is relatively constant (Basins 1-20), we calculate the local slope distributions within the most extensive lithologic units. The mean and one standard deviation of these distributions are shown in Fig. 5. The three highest-grade units of the basement group, PM1 (gneisses), PM2 (marbles), and PM3 (greenschists) have mean slopes of $32^{\circ}-34^{\circ}$, and the Tertiary units (MI and Ep) and the lowest-grade unit of the basement group (PM4) have mean slopes of $29^{\circ}-30^{\circ}$. Note that the increase in mean local slope from the southernmost basins to $100 \mathrm{~km} \mathrm{~N}$ (Fig. 3C) occurs almost entirely within the three lithologic units with the lowest average slopes (MI, Ep and PM4), indicating spatial variations within, as well as between, lithologic units.

\subsection{Drainage network}

Conventional wisdom holds that drainage networks obey certain scaling laws (Rodríguez-Iturbe and Rinaldo, 1997). Here, we use a simple measure, the Hack exponent, to test whether network organization changes through the transition from pre-SS to SS topography. Hack (1957) proposed a functional relationship between basin area, $A$, and the divide-to-outlet length of the main-stem river, $L$ :

$L \propto A^{H}$

where $H$ is commonly called the Hack exponent. Hack's (Hack, 1957) analysis of basins over a wide range of areas 
$\left(\sim 1-1000 \mathrm{~km}^{2}\right)$ yielded an $H$ value of 0.56 . As applied to individual drainage basins, Eq. (1) can be inverted:

$A \propto x^{1 / H}$,

to express the contributing area as a function of downstream distance, $x$, along the main-stem river. We calculate the Hack exponent of each main-stem river by linear regression of the logarithms of contributing area and downstream distance.

Fig. 3E shows the best-fit values and one standard error of the Hack exponent plotted against distance of the basin outlet from the southern tip of the island. Note that the correlation coefficients of all the regressions exceed 0.95. With the exception of Basin 32, which has an $H$ value of 0.49 , the values have a mean of 0.57 and range from 0.53 to 0.63 with no apparent spatial trend along the range.

\section{River profile analyses}

The longitudinal form of a main-stem river is an important characteristic of the landscape and reflects both the local and basin-wide competition between rock uplift, sediment supply and transport and channel lowering by erosion. As such, it is sensitive to both temporal and spatial variability in factors such as the rock uplift rate, precipitation rate and substrate erodability. Moreover, in responding to temporal changes in, for instance, rock uplift rate, main-stem rivers communicate these changes to the rest of a drainage basin. Thus, evidence of temporal or spatial variability from the form of the main-stem river is suggestive of similar conditions in the rest of a drainage basin. Because of this, river profile analysis is useful for gaining insight into the causes of topographic variability.

\subsection{Profile concavity}

Often, the longitudinal profile of mountain rivers can be described by a power-law relationship between the channel slope, $S$, and the contributing area, $A$ :

$S \propto A^{-\theta}$

where $\theta$ is the profile concavity (Willgoose et al., 1991b; Whipple and Tucker, 1999). Much work has gone into understanding the variability of the concavity in natural channels. In particular, Whipple and Tucker (1999) argue that the concavity, in the absence of variable rock uplift or precipitation, is limited to a nar- row range of values $(0.4-0.6)$. Work by Kirby and Whipple (2001) and Roe et al. (2002) demonstrates that non-uniform patterns of rock uplift and precipitation can significantly expand the range of expected concavities (to $0.4-2.1$ ).

We extract the main-stem river profiles from each of the CR basins, remove all flat segments, and calculate the slope of the profile by linear regression of the elevation-distance data within a moving window (Tomkin et al., 2003). We chose a window length of $1 \mathrm{~km}$ because it is short relative to the total length of the profiles yet long enough to filter most of the artifacts created during filling of the original DEM. Even after filtering, perturbations in the slope-area data are ubiquitous: in some instances, the noise is a record of knickzones that are identifiable in the elevation profile whereas others represent DEM artifacts and more subtle features.

Not all CR river profiles reasonably conform to a power-law slope-area relationship (Eq. (3)). For those that do, we calculate the concavity by least-squares regression of the logarithms of the slope-area data. The smoothest profiles yield values that are relatively invariant with respect to the details of the analysis, e.g., small changes in the window length and in the bounds of the regression. River profiles from Basins 23-33 are smoother and yield better fits than most profiles from northern basins. Irregularities in most of the northern profiles are significant enough to preclude the calculation of meaningful concavity values.

The best-fit concavity values for the smooth CR profiles are given in Table 1. The concavity values range from 0.52 in Basin 33 to 1.54 in Basin 7. Two

Table 1

Concavity values $(\theta)$ for smooth CR river profiles

\begin{tabular}{lrl}
\hline Basin & Area $\left(\mathrm{km}^{2}\right)$ & $\theta$ \\
\hline 2 & 562 & 0.77 \\
3 & 48 & 0.78 \\
5 & 119 & 0.72 \\
7 & 44 & 1.54 \\
18 & 120 & 1.41 \\
20 & 41 & 1.30 \\
23 & 211 & 0.54 \\
24 & 140 & 1.01 \\
25 & 132 & 0.96 \\
26 & 108 & 0.78 \\
27 & 54 & 0.94 \\
29 & 68 & 0.90 \\
30 & 110 & 0.65 \\
31 & 122 & 0.95 \\
32 & 97 & 0.95 \\
33 & 300 & 0.52 \\
\hline
\end{tabular}



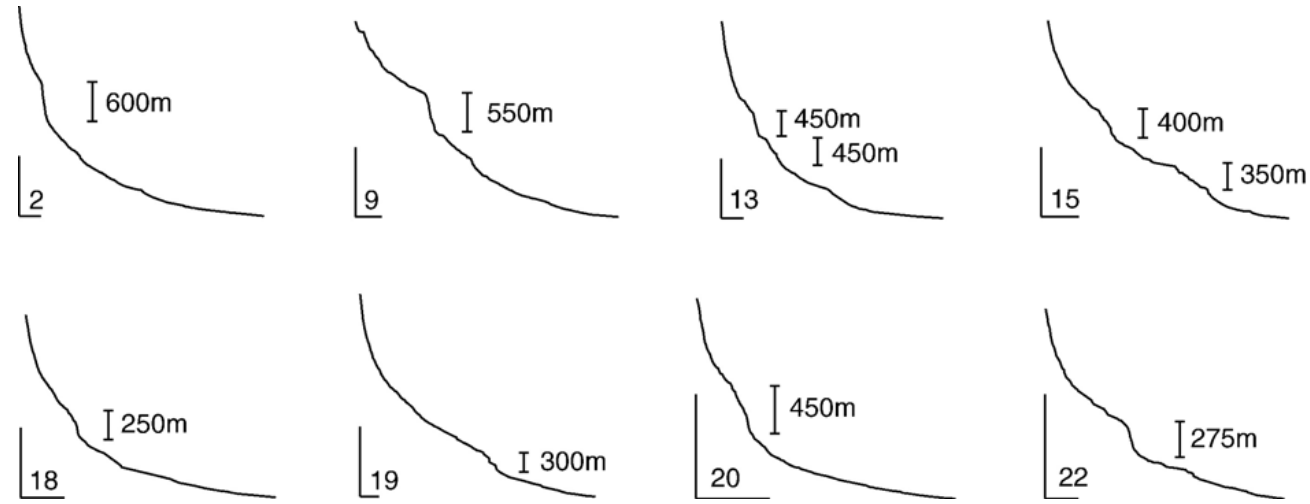

Fig. 6. River profiles with prominent knickzones. Horizontal and vertical scales are $5 \mathrm{~km}$ and $1 \mathrm{~km}$, respectively, such that the vertical exaggeration varies by profile.

of the three highest values occur in small basins (Basins 7 and 20) that do not extend to the CR divide. There does not appear to be a significant difference in the concavity between basins in the western and eastern CR.

\subsection{Knickzones}

Many of the CR river profiles that do not follow a power-law slope-area relationship are punctuated by fairly abrupt changes in channel elevation, or knickzones. We document the location and relief of ten knickzones along eight $\mathrm{CR}$ river profiles (Figs. 4 and 6). To avoid misinterpretation of DEM artifacts, we only consider knickzones with relief greater than $100 \mathrm{~m}$. The knickzones range in relief from $250 \mathrm{~m}$ to $600 \mathrm{~m}$ and in length from $0.6 \mathrm{~km}$ to $4.5 \mathrm{~km}$ (Fig. 6). Individual knickzones contribute $10 \%-40 \%$ of the total relief of the main channel. In Basins 13 and 15, which each have two knickzones, the cumulative proportions are $25 \%$ and $30 \%$, respectively.

Eight of the ten knickzones occur within $2.5 \mathrm{~km}$ of mapped lithologic boundaries (Fig. 4). The two exceptions are the prominent knickzone in Profile 9 and a smaller knickzone in Profile 19, which lies completely within the PM3 (greenschist) unit: the symbol denoting the lower knickzone on Profile 15 covers a small exposure of ultramafic rocks. Knickzone location is not simply related to an upstream transition from younger to older units or vice versa (Fig. 4). In Basins 20 and 22, knickzones occur at upstream transitions from Tertiary units to pre-Tertiary basement units whereas, in Basin 18, a knickzone occurs at an upstream transition from a basement unit to a Tertiary unit. The knickzone in Basin 2 occurs at an upstream transition from older to younger Tertiary units.

\section{Discussion}

\subsection{Topographic steady state}

The analyses of orogen size, regional topographic slope, basin hypsometry and local topographic slope reveal a consistent transition in the topography at 100$125 \mathrm{~km} \mathrm{~N}$, as shown by four key metrics. 1) The trends of cross-sectional area, mean elevation and maximum elevation indicate that the island has a roughly constant size from $125 \mathrm{~km} \mathrm{~N}$ to $275 \mathrm{~km} \mathrm{~N}$ and that growth to this form occurs gradually from the southern tip of the island (Fig. 3A). 2) The smoothed profiles of regional topographic slope for the WCR and ECR show that slopes increase from near zero at the southern tip of the island and remain relatively steady $\left(2^{\circ}-3^{\circ}\right.$ and $4.5^{\circ}-5.5^{\circ}$, respectively) from $100 \mathrm{~km} \mathrm{~N}$ to $200 \mathrm{~km} \mathrm{~N}$. 3) The value of the hypsometric integral increases at $100 \mathrm{~km} \mathrm{~N}$, delimiting a northern population of basins with values greater than 0.39 from a southern population with lower values. 4) Local topographic slopes increase from the south to $100 \mathrm{~km} \mathrm{~N}$ and maintain a relatively steady value $\left(30^{\circ}-35^{\circ}\right)$ until $200 \mathrm{~km} \mathrm{~N}$.

Assuming a space-time equivalence between distance along the island and duration of sub-aerial erosion, we infer that the growth to a steady form represents the attainment of a large-scale topographic SS (Suppe, 1981). Given a collision propagation rate of $55 \mathrm{~mm} / \mathrm{yr}$ (Byrne and Liu, 2002) and the observed transitions in the topography at $100-125 \mathrm{~km} \mathrm{~N}$, the time to SS is $1.8-$ 2.3 Myr after sub-aerial exposure.

The estimated time to SS supports the numerical modeling results of Howard (1994), who found that, for a range of external forcing, topographic SS was attained after erosion removed the equivalent of three times the landscape relief. In Taiwan, long-term erosion rates are thought to be $3-5 \mathrm{~km} / \mathrm{Myr}$ ( $\mathrm{Li}, 1976$; Willett et al., 
Table 2

Estimates of regional variability in the topographic steady state region

\begin{tabular}{lllc}
\hline Analysis & Mean & Standard deviation & C.V. (\%) \\
\hline Cross-sectional area & $110 \mathrm{~km}^{2}$ & $20 \mathrm{~km}^{2}$ & 18 \\
Mean elevation & $1.3 \mathrm{~km}$ & $0.21 \mathrm{~km}$ & 16 \\
Maximum elevation & $3.4 \mathrm{~km}$ & $0.26 \mathrm{~km}$ & 8 \\
Regional slope (WCR) & $2.6^{\circ}$ & $0.43^{\circ}$ & 17 \\
Regional slope (ECR) & $5.0^{\circ}$ & $0.98^{\circ}$ & 20 \\
Hypsometric integral & 0.47 & 0.04 & 9 \\
Mean local slope & $33^{\circ}$ & $1.9^{\circ}$ & 6 \\
Hack exponent & 0.57 & 0.03 & 5 \\
\hline
\end{tabular}

C.V.-coefficient of variation is defined as the one hundred times the ratio of the standard deviation and the mean; Steady-state region extends from $125 \mathrm{~km} \mathrm{~N}$ to $250 \mathrm{~km} \mathrm{~N}$. WCR - Western Central Range; ECR - Eastern Central Range; North of $225 \mathrm{~km} \mathrm{~N}$, the regional slope of the WCR is taken up to the crest of the Hsuehshan Range (dashed squares in Fig. 3B).

2003), and the topographic relief is roughly $3 \mathrm{~km}$ along much of the island. Hence, the predicted time to topographic SS is $1.8-3 \mathrm{Myr}$.

The northern limit of the SS region is located between $250 \mathrm{~km}$ and $300 \mathrm{~km} \mathrm{~N}$ (Fig. 3A and B). Given the collision propagation velocity, this implies that the topography in the northern and southern portions of the $\mathrm{SS}$ region differ in age by approximately $3 \mathrm{Myr}$ but have essentially the same form.

\subsection{Topographic variability in the steady state region}

Of the five cross-island swath and drainage basin analyses, results from four analyses exhibit broad trends that we infer to be related to the transition to steady state topography. However, the SS region, even considered in isolation, still exhibits considerable variability in morphological parameters. In Table 2, we show the mean and standard deviation of the measurements made in the SS region for each of the cross-island swath and drainage basin analyses. Also shown is the standard deviation as a percentage of the mean, or the coefficient of variation.

In general, the variability in the swath analysis parameters is twice as large as the variability in the basin characteristics. As noted before, large-scale structure appears to play an important role: the Yushan Range and Hsuehshan Range are clearly expressed in the trends of cross-sectional area and mean elevation (Fig. 3A). Lithology also plays a role: the highest mean local slopes are associated with exposure of the PM3, PM2 and PM1 units (Gilbert, 1877) in the northern portion of the ECR. The connection between local slope, lithology and duration of exhumation implies a possible obstacle for attaining topographic steady slope, at least as measured by local slope. We note that: 1) similar lithologic belts extend along most of the length of the ECR, and 2) the degree of metamorphism of the rocks exposed in the ECR increases towards the north along with the inferred duration of exhumation. If, for a given protolith, rock strength increases with the degree of metamorphism, the rock strength at a fixed point in the ECR will increase with time, and so will the local topographic slope. The magnitude of the variation in rock strength will depend on the protolith and $\mathrm{P}-\mathrm{T}-\mathrm{t}$ path of metamorphic rocks exposed at the surface.

Finally, the coincidence of many of the knickzones with mapped lithologic boundaries suggests persistent and relatively abrupt upstream changes in either or both rock uplift rate and rock strength. That is, knickzones might form at these boundaries as a result of an upstream-increase in rock uplift rate or, alternatively, form farther downstream and propagate until slowing at an upstream-increase in rock strength (Crosby and Whipple, 2006). As mapped at the 1:500,000 scale (Ho, 1988), the knickzones occur at transitions from both younger-to-older units and from older-to-younger units, though it is certainly possible that unmapped, smallerscale variations in rock strength might be capable of slowing a migrating knickzone. Alternatively, lithologic contacts might not be conformable and might instead represent active faults. Distinguishing between lithologic and tectonic controls on knickzone location would require more detailed mapping of the eastern Central Range.

\section{Conclusions}

Topographic steady state in Taiwan is expressed by the existence and coincidence of transitions in several characteristics of the landscape approximately 100 $125 \mathrm{~km} \mathrm{~N}$ of the southern tip of the island. Assuming that the collision between the Eurasian continental margin and the Luzon Arc has propagated southwards at a rate of $55 \mathrm{~mm} / \mathrm{yr}$, a topographic $\mathrm{SS}$ is achieved 1.8-2.3 Myr after emergence above sea level. All the analyses indicate that significant physiographic variability can exist in a landscape that is in a large-scale topographic SS. At the regional scale $(\sim 100 \mathrm{~km})$, topographic variability can be attributed to large-scale structure (e.g., uplift of the Yushan and Hsuehshan Ranges). Local slope and river profile analyses suggest variations in rock strength and/or rock uplift rate, which might account for some of the observed variability.

For many of the basin and river profile analyses, anomalous measurements are typically associated with smaller basins. Significant swath-to-swath and basin-to- 
basin differences in regional topographic slope, hypsometric integral, mean local slope, and profile concavity also suggest that variability in the topography would most likely preclude the recognition of SS by smallerscale studies of topography. Thus, even in a setting like Taiwan, topographic SS is revealed only by broad spatial transitions between pre-SS and SS landscapes.

\section{Acknowledgements}

We thank an anonymous reviewer for helpful comments. This work was supported by a National Science Foundation (NSF) Graduate Research Fellowship to Stolar.

\section{References}

Ahnert, F., 1970. Functional relationships between denudation, relief, and uplift in large mid-latitude drainage basins. Am. J. Sci. 268 (3), 243-263.

Burbank, D.W., Leland, J., Fielding, E., Anderson, R.S., Brozovic, N., Reid, M.R., Duncan, C., 1996. Bedrock incision, rock uplift and threshold hillslopes in the northwestern Himalayas. Nature 379 (6565), 505-510

Byrne, T.B., Liu, C.-S., 2002. Preface: introduction to the geology and geophysics of Taiwan. Geology and Geophysics of an Arccontinent Collision, Taiwan. Geological Society of America, Boulder, CO.

Clark, M.B., Fisher, D.M., Lu, C.Y., Chen, C.H., 1993. Kinematic analyses of the Hsuehshan Range, Taiwan - a large-scale pop-up structure. Tectonics 12 (1), 205-217.

Crosby, B.T., Whipple, K.X., 2006. Knickpoint initiation and distribution within fluvial networks: 236 waterfalls in the Waipaoa River, North Island, New Zealand. Geomorphology 82 (1-2), 16-38.

Dahlen, F.A., 1984. Noncohesive critical Coulomb wedges — an exact solution. J. Geophys. Res. 89 (NB12), 125-133.

Gilbert, G.K., 1877. Report on the geology of the Henry Mountains. U.S. Geographical and Geological Survey of the Rocky Mountain Region, Government Printing Office, Washington D.C., p. 170.

Hack, J.T., 1957. Studies on Longitudinal Profiles in Virginia and Maryland. United States Geological Survey, Washington D.C., p. 294.

Hilley, G.E., Strecker, M.R., Ramos, V.A., 2004. Growth and erosion of fold-and-thrust belts with an application to the Aconcagua foldand-thrust belt, Argentina. J. Geophys. Res. B. Solid Earth 109 (B01410). doi:10.1029/2002JB002282.

Ho, C.S., 1988. An introduction to the geology of Taiwan: explanatory text of the geological map of Taiwan. Central Geological Survey and Ministry of Economic Affairs, Taipei. 192 pp.

Howard, A.D., 1994. A detachment-limited model of drainage-basin evolution. Water Resour. Res. 30 (7), 2261-2285.

Kirby, E., Whipple, K., 2001. Quantifying differential rock-uplift rates via stream profile analysis. Geology 29 (5), 415-418.
Koons, P.O., 1990. 2-sided orogen-collision and erosion from the sandbox to the Southern Alps, New-Zealand. Geology 18 (8), $679-682$.

Lee, T.-Q., Kissel, C., Barrier, E., Laj, C., Chi, W.-R., 1991. Paleomagnetic evidence for a diachronic clockwise rotation of the Coastal Range, eastern Taiwan. Earth Planet. Sci. Lett. 104, $245-257$.

Lee, J.-C., Angelier, J., Chu, H.-T., Hu, J.C., Jeng, F.-S., 2001. Continuous monitoring of an active fault in a plate suture zone: a creepmeter study of the Chihshang Fault, eastern Taiwan. Tectonophysics 333, 219-240.

Li, Y.H., 1976. Denudation of Taiwan island since the Pliocene epoch. Geology 4, 105-107.

Liu, T.-K., Hsieh, S., Chen, Y.-C., Chen, W.-S., 2001. Thermokinematic evolution of the Taiwan oblique-collision mountain belt as revealed by zircon fission track dating. Earth Planet. Sci. Lett. 186 (1), 45-56.

Montgomery, D.R., 2001. Slope distributions, threshold hillslopes, and steady-state topography. Am. J. Sci. 301 (4-5), 432-454.

Montgomery, D.R., Brandon, M.T., 2002. Topographic controls on erosion rates in tectonically active mountain ranges. Earth Planet. Sci. Lett. 201 (3-4), 481-489.

Rodríguez-Iturbe, I., Rinaldo, A., 1997. Fractal River Basins. Cambridge University Press, New York. 565 pp.

Roe, G.H., Montgomery, D.R., Hallet, B., 2002. Effects of orographic precipitation variations on the concavity of steady-state river profiles. Geology 30 (2), 143-146.

Strahler, A.N., 1952. Hypsometric (area-altitude) analysis of erosional topography. Geol. Soc. Amer. Bull. 63, 1117-1142.

Suppe, J., 1981. Mechanics of mountain building and metamorphism in Taiwan. Mem. Geol. Soc. China 4, 67-89.

Teng, L.S., 1987. Stratigraphic records of the late Cenozoic Penglai orogeny of Taiwan. Acta Geol. Taiwan 25, 205-224.

Teng, L.S., 1996. Extensional collapse of the northern Taiwan mountain belt. Geology 24, 949-952.

Tomkin, J.H., Brandon, M.T., Pazzaglia, F.J., Barbour, J.R., Willett, S.D., 2003. Quantitative testing of bedrock incision models for the Clearwater River, NW Washington state. J. Geophys. Res. B. Solid Earth 108 (B6).

Whipple, K.X., Tucker, G.E., 1999. Dynamics of the stream-power river incision model: implications for height limits of mountain ranges, landscape response timescales, and research needs. J. Geophys. Res. B. Solid Earth 104 (B8), 17661-17674.

Willett, S.D., Brandon, M.T., 2002. On steady states in mountain belts. Geology 30 (2), 175-178.

Willett, S.D., Fisher, D., Fuller, C., En-Chao, Y., Lu, C.Y., 2003. Erosion rates and orogenic-wedge kinematics in Taiwan inferred from fission-track thermochronometry. Geology 31 (11), 945-948.

Willgoose, G., Bras, R.L., Rodriguez-Iturbe, I., 1991a. A coupled channel network growth and hillslope evolution model. 1. Theory. Water Resour. Res. 27 (7), 1671-1684.

Willgoose, G., Bras, R., Rodriguez-Iturbe, I., 1991b. A physical explanation of an observed link area-slope relationship. Water Resour. Res. 27 (7), 1697-1702.

Yu, S.-B., Chen, H.-Y., Kuo, L.-C., 1997. Velocity field of GPS stations in the Taiwan area. Tectonophysics 274, 41-59. 